\title{
CT Scans of Asbestos Cement Pipes as a Reference for Condition Assessment of Water Mains
}

\author{
Karel van Laarhoven ${ }^{1, * \mathbb{D}}$, Jip van Steen ${ }^{1}$, Frank van der Hulst ${ }^{2}$ and Hector Hernandez Delgadillo ${ }^{2} \mathbb{D}$ \\ 1 KWR Water Research Institute, 3433 PE Nieuwegein, The Netherlands; Jip.van.steen@kwrwater.nl \\ 2 Acquaint B.V., 8912 AV Leeuwarden, The Netherlands; Frank@acquaint.eu (F.v.d.H.); \\ Hector@acquaint.eu (H.H.D.) \\ * Correspondence: karel.van.laarhoven@kwrwater.nl
}

Citation: van Laarhoven, K.; van Steen, J.; van der Hulst, F.; Hernandez Delgadillo, H. CT Scans of Asbestos Cement Pipes as a Reference for Condition Assessment of Water Mains. Water 2021, 13, 2391. https://doi.org/10.3390/w13172391

Academic Editors: Francesco De Paola and Bruno Brunone

Received: 29 April 2021

Accepted: 20 August 2021

Published: 30 August 2021

Publisher's Note: MDPI stays neutral with regard to jurisdictional claims in published maps and institutional affiliations.

Copyright: (c) 2021 by the authors. Licensee MDPI, Basel, Switzerland. This article is an open access article distributed under the terms and conditions of the Creative Commons Attribution (CC BY) license (https:// creativecommons.org/licenses/by/ $4.0 /)$.

\begin{abstract}
The water distribution network of The Netherlands contains around 30,000 km of asbestos cement (AC) pipes, which constitutes around $25 \%$ of the total network. As a pipe material, AC has a relatively poor performance, and therefore is a high priority for renewal. To help decide an effective order of replacement, the water utilities need condition assessment techniques that help them determine which pipes have the highest risk of failure. In the presented work, X-ray computed tomography (CT) was used to measure the degradation of AC pipes taken out of the field. These scans provide a description of the pipe degradation with unmatched detail. The results are compared with strength tests performed on the same pipes, revealing that detailed knowledge of the complete pipe degradation is more important than previously assumed. Moreover, comparison of the CT results to those of a commercial, non-destructive inspection technique was used as a new avenue for validation of this technique, demonstrating its future usefulness for attaining the detailed measurement of pipe degradation required by water utilities.
\end{abstract}

Keywords: condition assessment; drinking water distribution network; asbestos cement; X-ray computed tomography; pulse echo ultrasound

\section{Introduction}

Being able to predict the condition of the drinking water distribution network is crucial for optimal asset management. In The Netherlands, asbestos cement (AC) still is an important pipe material: roughly $25 \%$ (around $30,000 \mathrm{~km}$ ) of the Dutch drinking water distribution network consists of this material. This pipe material has a relatively poor performance and, by extension, is a high priority for renewal. Still, replacing 30,000 km of pipes is a task that will take decades. This makes the development of condition assessments for AC especially important, so that water utility experts may use those to effectively identify the worst pipes and prioritize them for replacement.

For condition assessments of AC pipes to be effective, it is crucial to have access to non-destructive, in-line techniques to measure the remaining wall thickness, the part of the pipe wall that has not yet been degraded by processes such as leaching and chemical attack. Internationally, several promising avenues of measurement based on either acoustic or electromagnetic wave reflection have been developed [1,2], some of which have the potential for defect detection in metallic pipes as well $[3,4]$. Specific implementations have been piloted in The Netherlands since the early 2000s, such as a repurposing of ground penetrating radar [5-7] and pulse echo ultrasound [8]. Validation of these non-destructive techniques has so far mainly depended on cost-intensive and destructive experiments, such as phenolphthalein staining of core drilled samples on a lab scale. These destructive experiments are cumbersome, and are only able to measure the state of an exceedingly small portion of a pipe. As a result, representatively detailed validation based on field samples has been out of reach so far. 
X-ray computed tomography (CT) can be used to visualize spatial differences in material within scanned objects. While the development of this technique has been mainly driven by its invaluable use in medical diagnostics [9], it is also a useful tool for nondestructive inspection of building materials $[10,11]$. In particular, it has been shown that the technique is suitable for identifying the different components of cement-based materials [12,13], and that the technique can be used to visualize the material changes associated with cement degradation through leaching [14]. In previous work, it was determined that X-ray computed tomography may indeed provide a detailed description of AC pipe degradation [15]. In that work, it was also revealed that the leaching of AC drinking water pipes occurs in a far less homogeneous way than is traditionally assumed [16-18].

In the work presented here, the CT scan data of excavated pipes from [15] is studied in more detail to reveal the different patterns of degradation that occur in practice. The CT data are then used to aid in the interpretation of strength tests that were performed on the same pipes to provide a better understanding of the level of detail at which degradation patterns need to be measured for effective condition assessments. Finally, the CT data are compared to degradation measurements that were performed on the same pipes with a commercial ultrasound scanner that is used in the field. This demonstrates CT's added value to support the validation of different non-destructive measurement techniques and help identify deficits in the ability of the current state of technology to provide water utilities with effective condition assessments in the field. As a result, the added value that CT scans may have for applied scientific research that informs the inspection and maintenance decisions of water utilities is revealed.

\section{Materials and Methods}

\subsection{AC Pipes}

In total, 28 uncoated AC pipe sections with internal diameters of $100 \mathrm{~mm}$ and with a length of approximately $1 \mathrm{~m}$ were collected from the drinking water distribution network by the water utilities Brabant Water, Dunea, and WML. Six of these pipe segments were dug up during the repair of a pipe burst, with care taken that an uncracked segment was collected; 22 of these segments were dug up during joint renewal activities with municipalities and other stakeholders, unrelated to recent failures. All pipes were unearthed from urban environments and buried in ill-characterized sandy soils. The specific dimensions and ages of the pipes are given in Table 1. The original wall thickness of each pipe was determined with a pair of calipers. The age at removal was inferred from the pipes' installation dates as registered by the water utilities. The manufacturer of the pipes has never been registered and could not be traced. The manufacturer of choice at the time of installation, however, was Eternit, according to experts from all three utilities.

All pipe segments were scanned with CT (see Section 2.2). The pipes were then subjected to strength tests (see Section 2.3) and scanned with CT again to identify the locations of the resulting cracks. Subsequently, 28 ultrasonic measurements were performed on a subset of 10 pipe segments. 
Table 1. Properties of the field samples.

\begin{tabular}{|c|c|c|c|c|}
\hline Segment ID & $\begin{array}{c}\text { Length } \\
( \pm 10 \mathrm{~mm})\end{array}$ & $\begin{array}{c}\text { Original Wall } \\
\text { Thickness } \\
( \pm \mathbf{0 . 5} \mathbf{~ m m})\end{array}$ & Age (y) & $\begin{array}{c}\text { Reason for } \\
\text { Removal }\end{array}$ \\
\hline D09930 & 870 & 17.0 & 63 & Renewal \\
\hline 168218 & 1040 & 14.8 & 47 & Nearby Failure \\
\hline $0026-1$ & 1010 & 15.0 & 61 & Renewal \\
\hline D10365-1 & 950 & 14.5 & 65 & Renewal \\
\hline D10915-1 & 1160 & 14.9 & 46 & Renewal \\
\hline D161290 & 980 & 15.1 & 52 & Renewal \\
\hline ONB03 & 890 & 15.6 & 46 & Nearby Failure \\
\hline P10427-01 & 890 & 14.8 & 52 & Renewal \\
\hline P10915 & 1070 & 11.8 & 46 & Renewal \\
\hline 177340 & 830 & 14.6 & 58 & Nearby Failure \\
\hline IC17055-1 & 810 & 14.8 & 98 & Renewal \\
\hline D09586-1 & 1170 & 13.0 & 65 & Renewal \\
\hline 177598 & 1140 & 12.5 & 59 & Nearby Failure \\
\hline 103679 & 890 & - & Unknown & Nearby Failure \\
\hline DUN04 & 1100 & $\overline{14}$ & 51 & Renewal \\
\hline 176851 & 940 & 14.6 & 61 & Nearby Failure \\
\hline WML01 & 760 & 15.6 & Unknown & Renewal \\
\hline D9691-1 & 940 & 11.8 & 53 & Renewal \\
\hline Blerick1 & 560 & - & Unknown & Renewal \\
\hline Blerick2 & 490 & - & Unknown & Renewal \\
\hline Blerick3 & 610 & - & Unknown & Renewal \\
\hline Blerick4 & 700 & - & Unknown & Renewal \\
\hline DUN01 & 1000 & $\overline{14}$ & 51 & Renewal \\
\hline DUN02 & 990 & 14 & 51 & Renewal \\
\hline DUN03 & 970 & 14 & 51 & Renewal \\
\hline DUN05 & 1060 & 14 & 51 & Renewal \\
\hline DUN06 & 840 & 14 & 48 & Renewal \\
\hline DUN07 & 940 & 14 & 48 & Renewal \\
\hline
\end{tabular}

\subsection{X-ray Computed Tomography}

CT images of the AC pipes were obtained with a medical scanner (Somatom Definition, Siemens). The electron beam was set to $250 \mathrm{~mA}$ and $140 \mathrm{kVp}$. Furthermore, the scanner was set to a pitch of $0.6 \mathrm{~mm}$, a rotation time of $0.5 \mathrm{~mm}$, and with a B50f kernel. With these settings, a cross-section was measured over every $1.5 \mathrm{~mm}$ of pipe length with a field of view of $150 \mathrm{~mm} \times 150 \mathrm{~mm}$ and a resolution of 512 pixels in each direction $(0.29 \mathrm{~mm}$ per pixel).

The resulting $\mathrm{CT}$ data took the form of a collection of slice images, each image depicting the material composition of a different cross section of the pipe. A custom image processing algorithm based on basic, public Python libraries was used to translate the images of CT slices to profiles of degraded and undegraded material in terms of angles and millimeters. The algorithm identifies degraded and undegraded cement in individual $\mathrm{CT}$ slices through grey value thresholding. Degradation around the pipe wall's cross-section is then determined by measuring degraded and undegraded pixels along rays from the crosssection's center of mass projected across the pipe wall under different angles. The algorithm's approach and individual steps were previously reported more extensively in [9].

\subsection{Strength Tests}

The unearthed AC pipe segments were subjected to strength tests in the lab of the Section Materials \& Environment of the faculty of Civil Engineering and Geosciences at Delft University (Delft, The Netherlands). The pipe segments were tested by placing them in a container filled with water and then gradually increasing the water pressure at the inside of the pipe until catastrophic failure. The pipe segment was sealed at two ends, as shown in Figure 1, one end being connected to a high-pressure pump that pumped water into the tested pipe at $25 \mathrm{~mL} / \mathrm{min}$. Each time, pumping proceeded until the gradual 
increase in pressure led to either pipe failure through cracking or to leakage of the seals at the end (seals typically failing at pressures upwards of 50 bar, well beyond the operation limits of the seals in drinking water practice). Whether a specific pipe failed during the strength tests is summarized in Table 2.

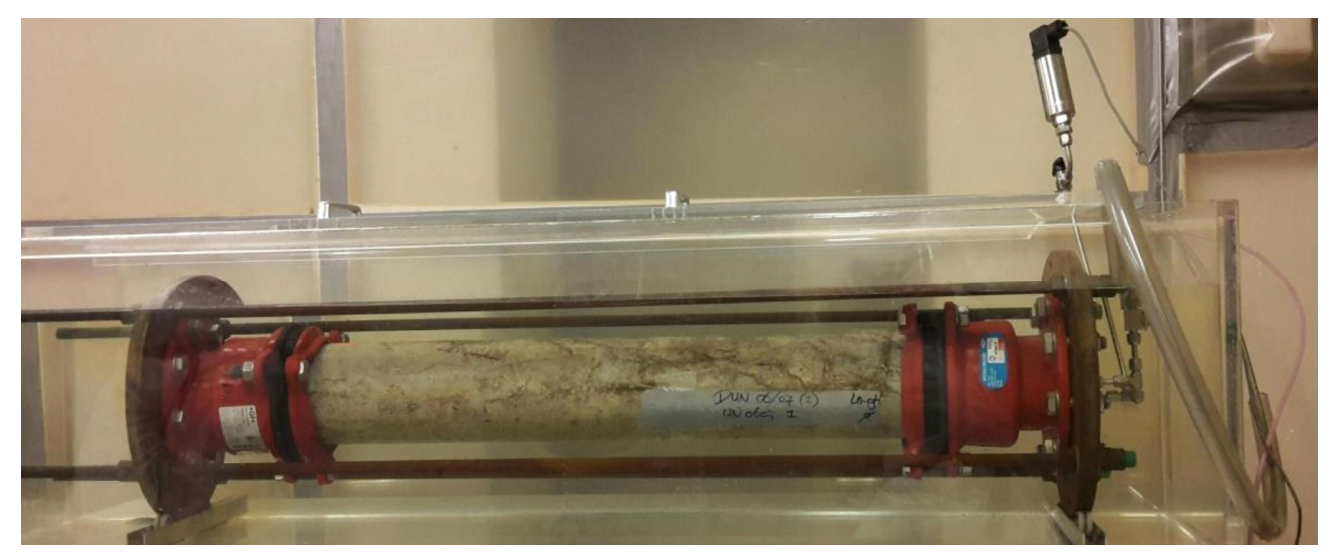

Figure 1. Test rig for the strength tests.

Table 2. Summary of pipe segment deterioration.

\begin{tabular}{|c|c|c|c|c|c|}
\hline Segment ID & $\begin{array}{l}\text { Failed during } \\
\text { Strength Test }\end{array}$ & $\begin{array}{l}\text { Internal } \\
\text { Material } \\
\text { Loss (\%) }\end{array}$ & $\begin{array}{c}\text { Homogeneity } \\
\text { of Internal } \\
\text { Degradation }\end{array}$ & $\begin{array}{l}\text { External } \\
\text { Material } \\
\text { Loss (\%) }\end{array}$ & $\begin{array}{c}\text { Homogeneity } \\
\text { of External } \\
\text { Degradation }\end{array}$ \\
\hline D09930* & Yes & 2 & 0.49 & 16 & 0.73 \\
\hline $168218^{*}$ & Yes & 18 & 0.73 & 2 & 0.32 \\
\hline $0026-1$ * & Yes & 22 & 0.89 & 7 & 0.42 \\
\hline D10365-1 & Yes & 40 & 0.92 & 18 & 0.57 \\
\hline D10915-1 & Yes & 6 & 0.47 & 41 & 0.91 \\
\hline D161290* & Yes & 5 & 0.55 & 8 & 0.39 \\
\hline ONB03 & Yes & 32 & 0.95 & 14 & 0.74 \\
\hline P10427-01 * & Yes & 6 & 0.65 & 4 & 0.39 \\
\hline P10915* & Yes & 2 & 0.51 & 7 & 0.29 \\
\hline 177340 * & Yes & 8 & 0.62 & 3 & 0.18 \\
\hline IC17055-1 & Yes & 19 & 0.84 & 34 & 0.72 \\
\hline D09586-1 * & Yes & 14 & 0.71 & 18 & 0.65 \\
\hline 177598 * & Yes & 6 & 0.5 & 8 & 0.23 \\
\hline 103679 * & Yes & 3 & 0.42 & 5 & 0.23 \\
\hline DUN04 & Yes & 4 & 0.51 & 6 & 0.39 \\
\hline 176851 & No & 26 & 0.83 & 25 & 0.72 \\
\hline WML01 & No & 23 & 0.95 & 6 & 0.25 \\
\hline D9691-1 & No & 4 & 0.68 & 14 & 0.68 \\
\hline Blerick1 & No & 23 & 0.96 & 1 & 0.24 \\
\hline Blerick2 & No & 21 & 0.96 & 1 & 0.23 \\
\hline Blerick3 & No & 22 & 0.95 & 1 & 0.26 \\
\hline Blerick4 & No & 22 & 0.95 & 0 & 0.19 \\
\hline DUN01 & No & 1 & 0.47 & 7 & 0.51 \\
\hline DUN02 & No & 2 & 0.45 & 8 & 0.55 \\
\hline DUN03 & No & 2 & 0.54 & 7 & 0.56 \\
\hline DUN05 & No & 4 & 0.48 & 7 & 0.47 \\
\hline DUN06 & No & 1 & 0.42 & 6 & 0.51 \\
\hline DUN07 & No & 1 & 0.43 & 4 & 0.56 \\
\hline
\end{tabular}

* Pipes selected for the analysis described in paragraph Section 3.2. 


\subsection{Ultrasound Measurements}

A commercial measurement device based on ultrasonic reflection (Pipescanner, Acquaint B.V.) was used to measure the remaining wall thicknesses of the AC pipes. The physical principles behind this technique were previously reported in [5]. Measurements were performed in tangential direction, rotating around the circumference of the pipe over 360 degrees. The orientations of the measurements with respect to physical markings on the pipes (i.e., cracks) were recorded in order to make alignment and comparisons of CT and ultrasonic measurements possible.

\section{Results}

\subsection{Degradation of $A C$}

To provide an overall impression of the degradation of a given pipe, height maps were constructed to summarize the information present in a complete CT scan. Examples are given in Figure 2 for the distinct typical degradation patterns that were observed among the pipes. The color represents the remaining wall thickness at a given position in the pipe as marked by the axis in terms of angle and distance along the length of the pipe segment. The lines of pixels with value 0 clearly identified cracks in the pipe due to failure during the strength tests (pipe $\mathrm{c}$ did not fail).
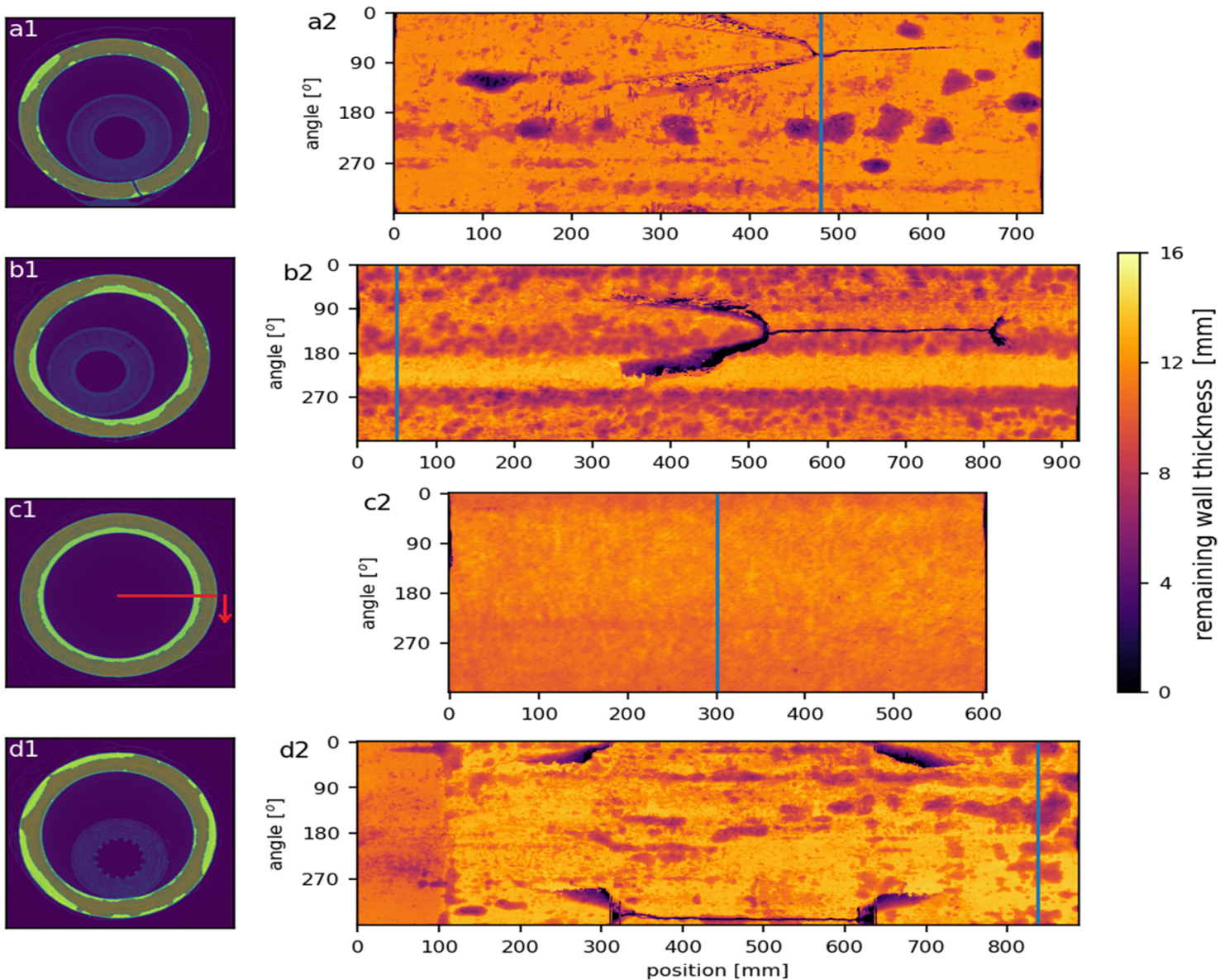

Figure 2. Four examples of degradation patterns of AC pipes as measured with CT. The ID's of the pipes in Table 1 are 103679 (a), 168218 (b), Blerick4 (c), and D161290 (d). The cross-sections (a1-d1) are the CT slices at the locations marked with the blue lines in the corresponding height maps of the pipes (a2-d2). The height maps indicate the remaining wall thickness of a pipe as a function of the angle around and position along the longitudinal pipe axis. The horizontal red line and the red arrow in (c1) demonstrate the origin and direction of the vertical angle axes in (a2-d2). 
The remaining wall thickness of the pipe in Figure 2a displays a spotty pattern across the pipe surface that corresponds to many localized areas of external degradation. In Figure $2 b$, internal and external degradation are drawn out in thin bands across the surface. The pipe in Figure $2 \mathrm{c}$ displays a far more even landscape, which corresponds to the homogeneous, internal degradation across the pipe wall that is considered to be typical for leaching AC pipes [10]. Figure $2 \mathrm{~d}$ again shows a somewhat spotty, inhomogeneous pattern, with degradation clearly being more pronounced at certain angles around the pipe's longitudinal axis.

To further quantify and summarize the degree of degradation for each pipe, the percentages of degraded material on the inner pipe wall and on the outer pipe wall were determined from the processed CT data. This was done by taking the sum of the original wall thicknesses at each location on the pipe (i.e., at each pixel of a height map) as a measure for the amount of original material, taking the sum of the thicknesses of the internally or externally degraded layer as a measure for the amount of degraded material and then evaluating the percentage of the degraded material compared to the original amount of material. The percentages are reported in Table 2 as the internal and external material loss.

To further quantify the distribution of internal and external degradation for each pipe, the following approach was used: first, number of pixels that contain $90 \%$ of (either internal or external) degradation is determined; second, the number equal to $90 \%$ of the total pixels on the pipe wall is determined; third, the ratio of the first and second number is taken. This way, a measure for homogeneity is obtained that is equal to 1 for a perfectly homogeneously degraded pipe (90\% of degradation smeared out over $90 \%$ of the pipe surface) and approaches 0 in cases where degradation is limited to a single location on the pipe wall. The ratios are reported in Table 2 as the homogeneity of internal and external degradation.

Note that it is inherent to these indicators that, for a given degraded wall thickness, a lower homogeneity implies a lower percentage of material loss. The average degradation thickness (as a percentage of the total wall thickness) may be estimated by dividing the percentage of material loss by the degree of homogeneity. For instance, a material loss of $6 \%$ and a homogeneity of 0.5 (the internal degradation of 177598) implies that, scattered across $50 \%$ of the pipe surface, there are spots of degradation that on average are as deep as at least $12 \%$ of the pipe wall thickness.

Table 2 shows that the patterns described above for the pipes displayed in Figure 2 were typical for the 28 pipes that were scanned in total. Only eight pipes had both a substantial amount of internal material loss (10\% or more) and a homogeneity of internal degradation that approached 1 (Blerick1 to 4, D10365-1, ONB03, WML01, 0026-1), the expected pattern of homogeneous internal degradation. The other pipes had a noticeable amount of inhomogeneity for varying degrees of material loss. At least five pipes (168218, 177340, 177598, D09586-1, D10915-1) displayed degradation of more than $10 \%$ of the pipe wall (estimated as \% material loss divided by the degree of homogeneity), confined to less than $75 \%$ of the surface.

Compared to internal degradation, the external degradation still had lower homogeneity values more frequently: nine (0026-1, D161290, P10427-01, P10915, 177340, 177595, 103679, DUN04, WML01) pipes displayed degradation of more than $10 \%$ of the pipe wall (estimated as \% material loss divided by the degree of homogeneity), confined to less than $42 \%$ of the surface (the lowest inhomogeneity observed for the internal degradation). Only one pipe had substantial external degradation with a homogeneity of more than 0.9 (D10915-1).

To further compare the complete datasets for internal and external degradation, a rough relation between material loss and inhomogeneity was fitted with an equation of the form $f(x)=a \cdot x+b$, with $f(x)$ the material loss, $x$ the homogeneity, and $a$ and $b$ the fit parameters. For internal degradation, this yielded $a=0.017 \pm 0.002$ and $b=0.46 \pm 0.02$, and for external degradation, this yielded $\mathrm{a}=0.017 \pm 0.002$ and $\mathrm{b}=0.29 \pm 0.03$. So, although inhomogeneous internal degradation occurs regularly, for a given percentage of 
material loss, the internal degradation on average is more homogeneous than the external degradation.

\subsection{Importance of Inhomogeneous Degradation}

Since inhomogeneous degradation turns out to be quite prevalent on both the internal and external pipe wall (see Table 2), the question arises whether a rough impression of the general level of degradation of AC mains is sufficient for a correct estimation of the risk of failure, or that detailed knowledge of the presence of potential weak links is required. To obtain a first indication of the importance of these spots of local degradation, the CT scans were used to further investigate the degradation around the point of origin of the cracks that occurred during the strength tests.

Figure 3 shows an example of how this was approached for pipe 177598: the location of the crack that resulted from the strength tests was obtained from the scans that were taken after the tests (Figure 3b). Subsequently, that information was combined with the scans that were taken prior to the strength tests (Figure 3a) to determine the original remaining wall thickness along the trajectory of the crack (Figure 3c). Since the crack's exact point of initiation could not be obtained from the CT scans, the part of the crack between forks was taken to be the first part of the crack, which formed directly after initiation. The distribution of remaining wall thicknesses along this part was compared to the distribution of the remaining wall thicknesses across the complete pipe wall (Figure 3d). In this particular case, indeed, one of the lowest values for the remaining wall thicknesses was found on the crack, and the wall thicknesses along the crack were clearly lower than those that were present elsewhere on the pipe, although there was a clear overlap in distributions as well. The minimum wall thickness on the crack belonged to the $0.07 \%$ lowest anywhere on the pipe.

This exercise was carried out for 10 pipes (see Table 2, the IDs marked with an asterisk) that failed during the strength tests. In 8 out of 10 cases, the minimum wall thickness on the crack belonged to the $1 \%$ smallest wall thicknesses anywhere on the pipe, like the example of Figure 3. In 2 out of 10 cases, at least $8 \%$ of the pipe wall had lower remaining wall thicknesses than anywhere on the crack, so that a clear connection between the location of the crack and the points of lowest wall thickness was not obvious. The fact that, in $80 \%$ of the studied cases, the crack included the $1 \%$ most degraded spots indicated that local spots of inhomogeneous degradation indeed influenced failure behavior, although the 10 cases studied here cannot provide a statistically representative basis for that conclusion. 

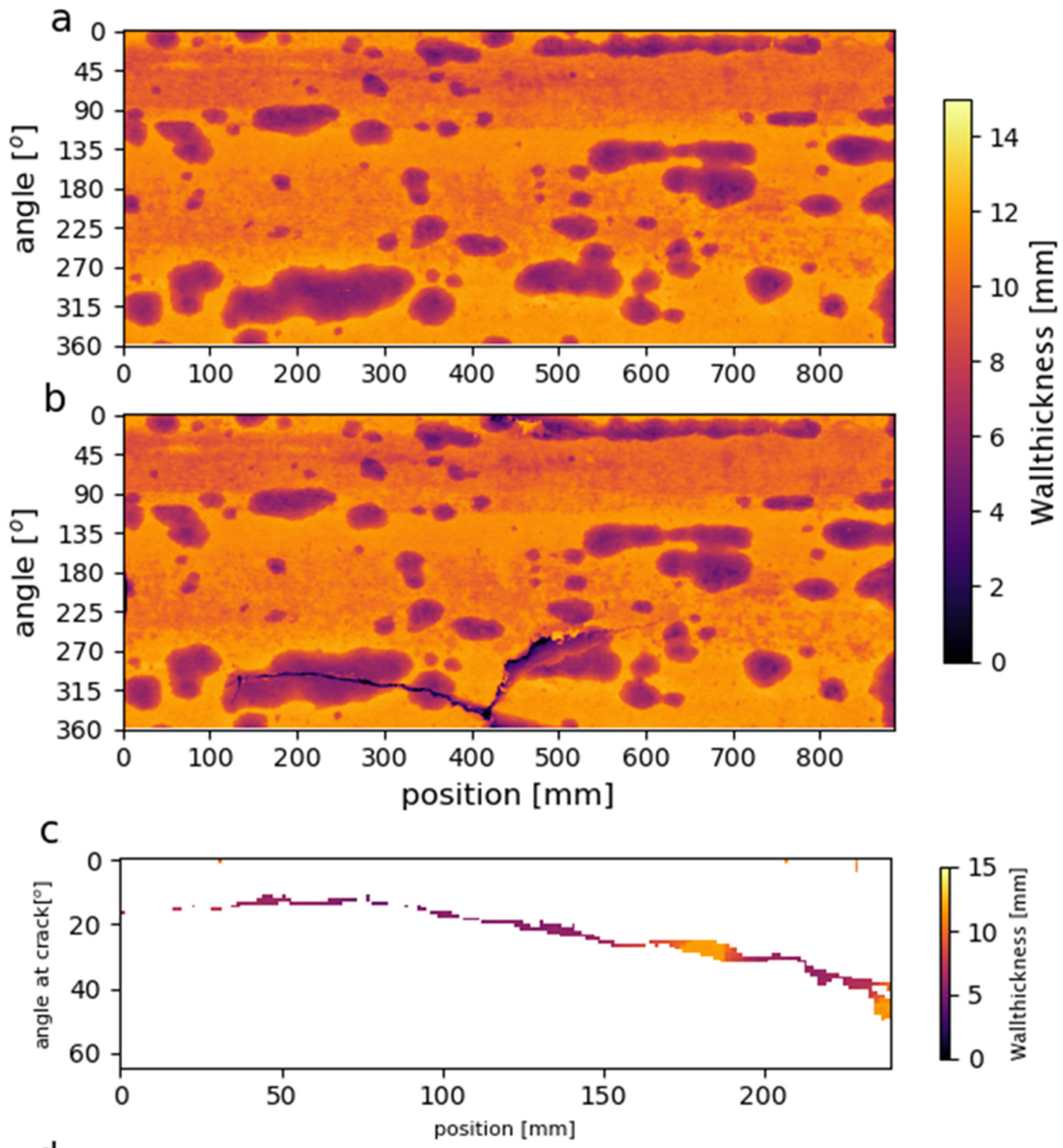

d

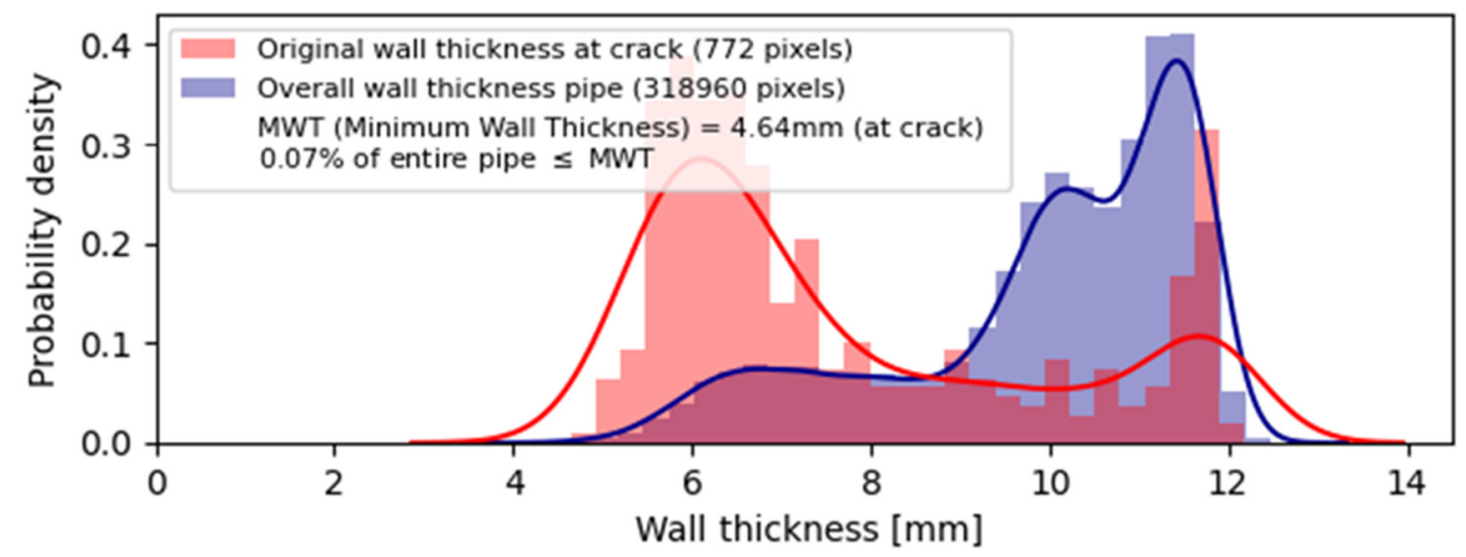

Figure 3. Approach for investigating an influence of local degradation on cracking. (a) The CT scan of pipe 177598 prior to the strength test; (b) The CT scan of the cracked pipe after the strength tests; (c) The remaining wall thicknesses in the first scan on the location of the crack in the second scan; (d) Normalized histograms of the distribution of wall thicknesses along the crack (red) and across the whole pipe (blue). 


\subsection{Comparrison with Ultrasound Measurements}

Figure 4 displays several comparisons of profiles made with the ultrasound technique (blue lines) with profiles extracted from the CT data (black lines for the local original wall thickness as determined from the $\mathrm{CT}$ data, red lines for the remaining wall thickness). The lettering of the profiles in Figure 4 corresponds to the lettering of Figure 2, and the profiles belong to the cross-sections shown in Figure 2 (a1-d1). For a correct comparison, it is important to note that a CT slice corresponded to a $1.5 \mathrm{~mm}$ cross-section of the pipe, which was relatively precise compared to the location of the ultrasonic measurement, which was carried out by hand. To account for human error, the minimum and maximum wall thickness encountered in a $1 \mathrm{~cm}$ band around the intended location $(0.5 \mathrm{~cm}$ on both sides) were marked by the red area around the CT profile.
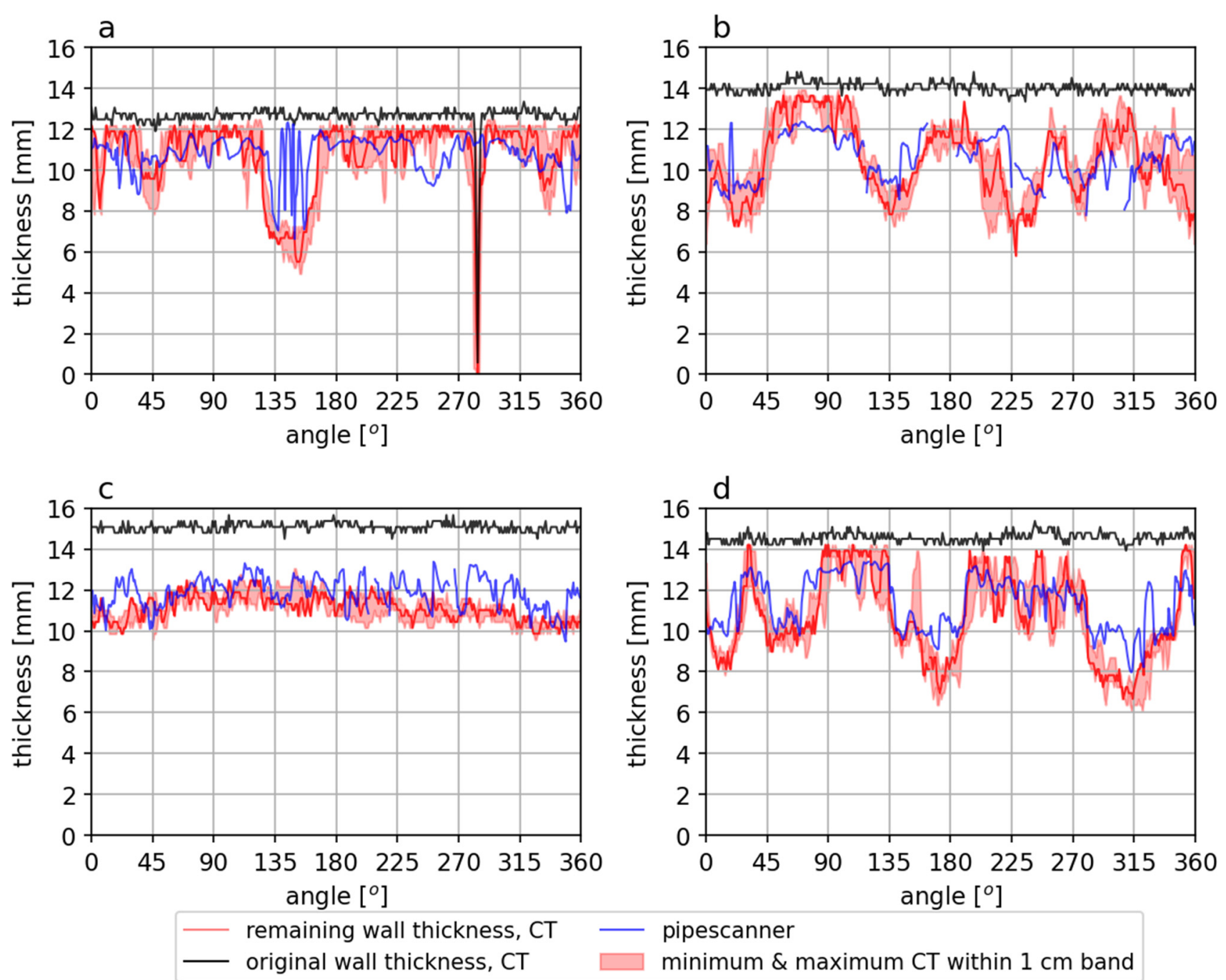

\section{pipescanner}

minimum \& maximum CT within $1 \mathrm{~cm}$ band

Figure 4. Comparison of CT (red) and ultrasound (blue) measurements of the remaining wall thicknesses of the four crosssections of degraded pipes shown in Figure 2 (the lettering (a-d) corresponds to pipes with the same letters in Figure 2). The black lines represent the original wall thickness (comprising degraded and undegraded material) as determined from the CT scans.

Overall, the ultrasound profiles matched the CT profiles quite well in terms of shape and order of magnitude. There were offsets in the order of a few $\mathrm{mm}$ at some locations, such as Figure $4 \mathrm{a}$ around $135^{\circ}$, Figure $4 \mathrm{~b}$ around $90^{\circ}$, and Figure $4 \mathrm{~d}$ around $90^{\circ}$. 


\section{Discussion and Conclusions}

\subsection{Implications for Assessing the Deterioration of AC in Drinking Water Practice}

$\mathrm{X}$-ray computed tomography is a well-understood and extensively developed technique that aims specifically to reveal material differences throughout solid objects. As such, CT is able to map degradation throughout AC pipes with a level of detail that is unmatched not only in terms of the accuracy with which it differentiates between degraded and undegraded materials, but also in terms of the large amount of information that is gained from scanning the complete pipe, as was previously shown in [15]. Especially the latter point adds an additional dimension to the measured degradation as compared to the line profiles that are typically obtained with staining techniques and more sophisticated sensors that are used in the field $[1,5-8,16]$.

Digging up pipes in order to scan them with $\mathrm{CT}$ is a destructive form of testing for all intents and purposes. As such, CT might not suit the drinking water practice in all cases due to the costs and effort involved. If the collection of field samples is scaled up and a sufficiently safe routine to prevent exposure to asbestos is chosen, however, costs and effort may be mitigated. At the moment of writing, several Dutch utilities are considering to pilot the use of $\mathrm{CT}$ as an advanced technique for exit assessments of pipes on a larger scale.

Even in the cases where CT is still not suitable for direct condition assessment, the technique may still provide high-quality references for the development and validation of more practical inspection techniques, like the ultrasound technique studied here. While the ultrasound measurements clearly captured the average level and general shape of these profiles well, the true minima in remaining wall thickness are occasionally missed by a few $\mathrm{mm}$. This type of detailed insight in the limitations of these techniques when applied in the field helps water utilities to apply suitable safety factors in their predictive maintenance while they use the inspection techniques available to them.

The large heterogeneity in the degradation patterns shown in Figure 2 and summarized in Table 2 demonstrates that multiple line profiles will need to be collected if the maximum degradation of a pipe is to be determined with some level of confidence. Moreover, the analysis of Section 3.2 indicates that it is indeed desirable to identify not only the average levels of degradation in pipes, but also the specific extent of degradation at the weakest spots. In the current common practice, Dutch utilities that use non-destructive tools in their condition assessments collect only a few length profiles with these tools, like they would with a regular staining test. This research shows that, in order to properly exploit modern in-line techniques, water utilities should clearly strive to use these for the collection of multiple line profiles per pipe with submillimeter accuracy. The comparison of the CT profiles with the profiles measured with a state-of-the-art commercial technique in Section 3.3 show that this is almost within reach for water utilities.

\subsection{Lessons Learned about the Deterioration of AC Drinking Water Pipes in General}

From a research perspective, radiographic methods like CT have, to our knowledge, not yet received substantial attention as a technique for studying the condition of $\mathrm{AC}[1,16]$. However, the technique unlocks the possibility to study the degradation phenomena that occur in AC in more detail. At the current state of knowledge, homogeneous degradation at a constant rate is typically assumed $[17,18]$. According to the results presented in Section 3.1, this assumption represents an exception rather than a rule, as inhomogeneous degradation was prevalent at both the inner and the outer pipe wall. The high precision of CT might prove valuable for studying aspects of AC degradation other than integrity loss through wall thickness reduction as well, such as the release of AC components and the formation of protective scaling layers during the degradation of the very first layers of the inner pipe wall, long before structural integrity of the pipe becomes an issue [19].

Presumably, the localized external degradation in Figure 2a-d stems from contact with un-homogeneously distributed aggressive soil components around the pipes while they were in use. The inhomogeneous nature of the internal degradation in Figure $2 a, b$ is more remarkable, however, since the leaching of calcium hydroxide from AC pipes into 
the drinking water is usually understood to be a diffusion controlled process that occurs homogeneously across the pipe surface [10], as was the case for the pipes like the one in Figure 2c. Research on the chemical (and possibly the microbiological) microclimate of the inner pipe wall in relation to local deterioration is needed to further explain this discrepancy. This would also require research on possible factors that lead to such local differences, such as fault production or installation, damage due to pressure surges, or water compositions that lead to inhomogeneous precipitation across the pipe wall or that support colonial microbial growth. Obtaining the historical operational data of water utilities required to study this may prove a challenge in itself.

During the strength tests, pipes failed only at pressures well beyond practical operating conditions. As such, the performance of the pipes during the pressure tests should not be taken as a proxy for pipe performance under operating conditions and the pressure tests are therefore poorly suited to provide a relation between the degradation profiles and pipe condition. To fully capture a relation between wall thickness, heterogeneous degradation, operating conditions, and, finally, a pipe's condition, research involving more detailed modelling of stresses in degraded pipe walls is needed to determine at which dimensions the weakest links will dominate the remaining life of pressured pipes.

Author Contributions: Conceptualization, K.v.L.; methodology, K.v.L.; validation, K.v.L., J.v.S., F.v.d.H. and H.H.D.; formal analysis, K.v.L. and J.v.S.; measurements, F.v.d.H. and H.H.D.; writingoriginal draft preparation, K.v.L.; visualization, K.v.L. and J.v.S. All authors have read and agreed to the published version of the manuscript.

Funding: This research was funded by the BTO joint research program of the Dutch water utilities, project numbers 400544-192, 402045-092, and 402045-213. The CT measurements were funded by the drinking water companies Brabant Water, Dunea, PWN, WMD, and WML.

Acknowledgments: The authors are grateful to the Dutch drinking water companies Brabant Water, Dunea, and WML for providing the pipe field samples on which the reported measurements were performed.

Conflicts of Interest: The authors declare no conflict of interest. The funders had no role in the design of the study; in the collection, analyses, or interpretation of data; in the writing of the manuscript, or in the decision to publish the results.

\section{References}

1. Liu, Z.; Kleiner, Y. State of the art review of inspection technologies for condition assessment of water pipes. Measurement 2013, 46,1-15. [CrossRef]

2. Gong, J.; Lambert, M.; Zecchin, A.; Simpson, A.; Arbon, N.; Kim, Y. Field study on non-invasive and non-destructive condition assessment for asbestos cement pipelines by time-domain fluid transient analysis. Struct. Health Monit. 2016, 15. [CrossRef]

3. Gong, J.; Lambert, M.; Simpson, A.R.; Zecchin, A. Detection of localized deterioration distributed along single pipelines by reconstructive MOC analysis. J. Hydraul. Eng. 2014, 140, 190-198. [CrossRef]

4. Meniconi, S.; Brunone, B.; Frisinghelli, M. On the role of minor branches, energy dissipation, and small defects in the transient response of transmission mains. Water 2018, 10, 187. [CrossRef]

5. Smolders, S.; Verhoest, L.; De Gueldre, G.; Van De Steene, B. Inspection of deteriorating asbestos cement force mains with georadar technique. Water Sci. Technol. 2009, 60, 995-1001. [CrossRef] [PubMed]

6. Slaats, P.; Mesman, G.; Rosenthal, L.; Brink, H. Tools to monitor corrosion of cement-containing water mains. Water Sci. Technol. 2004, 49, 33-39. [CrossRef] [PubMed]

7. Berndt, M.; Davis, P. Non destructive testing condition assessment of asbestos cement pipes. In Proceedings of the Ozwater Convention and Exhibition, Melbourne, Australia, 1 January 2009.

8. Delgadillo, H.H.; Kern, B.; Loendersloot, R.; Yntema, D.; Akkerman, R. A methodology based on pulse-velocity measurements to quantify the chemical degradation levels in thin mortar specimens. J. Nondestruct. Evaluation 2018, 37, 79-92. [CrossRef] [PubMed]

9. Hoheisel, M. Review of medical imaging with emphasis on X-ray detectors. Nucl. Instrum. Methods. Phys. Res 2016, 563, 215-224. [CrossRef]

10. Plessis, A.; Boshoff, W.P. A review of X-ray computed tomography of concrete and asphalt construction materials. Constr. Build. Mater. 2019, 199, 637-651. [CrossRef]

11. Kong, W.; Wei, Y.; Wang, S.; Chen, J.; Wang, Y. Research progress on cement-based materials by X-ray computed tomography. Int. J. Pavement Res. Technol. 2020, 13, 366-375. [CrossRef] 
12. Aruntas, H.Y.; Tekin, I.; Birgul, R. Determining Hounsfield unit values of mortar constituents by computerized tomography. Measurement 2010, 43, 410-414. [CrossRef]

13. Wan, K.; Chen, L.Y.; Xu, Q. Calibration of grayscale values of cement constituents using industrial X-ray tomography. Sci. China 2015, 58, 485-492. [CrossRef]

14. Wan, K.; Li, Y.; Sun, W. Application of tomography for solid calcium distributions in calcium leaching cement paste. Constr. Build. Mater. 2012, 36, 913-917. [CrossRef]

15. Laarhoven, K.v.; Quintiliani, C. CT Scans of asbestos cement pipes to support the development of better condition assessments. Environ. Sci. Proc. 2020, 2, 11. [CrossRef]

16. Leroy, P.; Shock, M.R.; Wagner, I.; Holtschulte, H. Cement-based materials. In Internal Corrosion of Water Distribution Systems, 2nd ed.; AWWA Denver: Denver, CO, USA, 1996.

17. Wols, B.; Moerman, A.; Horst, P.; Laarhoven, K.v. Prediction of pipe failure in drinking water distribution networks by Comsima. Proceedings 2018, 2, 589. [CrossRef]

18. Punurai, W.; Davis, P. Prediction of asbestos cement water pipe aging and pipe prioritization using Monte Carlo simulation. Eng. J. 2017, 21, 1-13. [CrossRef]

19. WHO. Asbestos in drinking-water. Background document for development of WHO Guidelines for Drinking-water Quality. In Guidelines for Drinking-Water Quality, 2nd ed.; Health Criteria and Other Supporting Information; World Health Organization: Geneva, Switzerland, 1996; Volume 2. 